\title{
Airborne Air Toxics Characteristics and Inhalation Health Risk Assessment of a Metropolitan Industrial Complex
}

\author{
Jiun-Horng Tsai ${ }^{1}$, Wei-Ting Gu${ }^{1}$, I-I Chung ${ }^{1}$, Hung-Lung Chiang, ${ }^{2,3 *}$ \\ ${ }^{1}$ Department of Environmental Engineering, National Cheng-Kung University, Tainan 70101, Taiwan \\ ${ }^{2}$ Department of Safety Health and Environmental Engineering, National Yunlin University of Science and Technology, \\ Yunlin 64002, Taiwan \\ ${ }^{3}$ Department of Occupational Safety and Health, China Medical University, Taichung 40402, Taiwan
}

\begin{abstract}
Air toxics, also well-known as hazardous air pollutants (HAPs), have significant health effects on human health and are of great concern. This paper studied a number of hazardous air pollutants in an industrial and metropolitan complex area in order to determine their ambient abundance and potential health impacts. The target pollutants in this study are benzene, formaldehyde, 1,3-butadiene, arsenic, 2,3,7,8-TCDD, and diesel particulate matter (DPM). A cancer risk assessment was conducted to determine the health effects of exposure to the six HAPs by using the AERMOD model. Results indicated that the emission of benzene, formaldehyde, 1,3-butadiene, arsenic and DPM was $184.5 ; 227.3 ; 68.0 ; 238$, and 316 ton year $^{-1}$, respectively, and the emission of 2,3,7,8-TCDD was 4,994 mg-TEQ year ${ }^{-1}$. Benzene (86\%), formaldehyde (69\%), and 1,3-butadiene (77\%) were mainly emitted from on-road mobile sources. Arsenic (70\%) and 2,3,7,8-TCDD (about 100\%) were mainly emitted from stationary sources and DPM was emitted from diesel engines, port operations and ocean-going vessels. Spatial air toxic distribution indicated that the highest concentration of DMP, benzene, formaldehyde, and 1.3-butadiene occurred on the highway and in the downtown district due to their high traffic volume. DPM occupied more than $80 \%$ of total cancer risk in the region, followed by 1,3-butadiene, benzene, formaldehyde, arsenic, and 2,3,7,8-TCDD. In the industrial and residential complex area, about $99 \%$ of the cancer risk stemmed from on-road vehicles and port operations due to hazardous air pollutant emissions, especially DPM. The control scenario was made huge efforts to reduce the emission, however the results indicated only reduced the overall cancer risk assessment by $10 \%-15 \%$. Policy makers have to think carefully about whether implementing the kind of emissions regulations simulated in this control scenario will need to be enhanced with additional measures to further reduce the risk of air pollution for human health.
\end{abstract}

Keywords: Hazardous air pollutants (HAPs); AERMOD model; Risk assessment.

\section{INTRODUCTION}

Air pollutants have a significant health effect on the world population, particularly in urban areas. They also have a considerable economic impact, cutting down on lives, increasing medical costs and reducing productivity through the loss of working days across the economy (EEA, 2018).

Approximately seven million premature deaths occur globally each year, representing one eighth of the total deaths worldwide due to the combined effects of ambient and household air pollution. Motorized road transport and household fuel combustion, together with agriculture and the burning of industrial coal are of special concern in terms of their contribution to the health impact of ambient and

\footnotetext{
${ }^{*}$ Corresponding author.

E-mail address: hlchiang@yuntech.edu.tw
}

household air pollution and consequent social costs (OECD, 2015). In 2013 exposure to air pollution (including ambient $\mathrm{PM}_{2.5}$, household $\mathrm{PM}_{2.5}$, and ozone) cost the world's economy \$5.11 trillion. In Asia, losses due to air pollution are estimated to be the equivalent of $7.4-7.5 \%$ of regional GDP (gross domestic product) (The World Bank, 2016).

In Europe, one study estimated that air pollution reduces mean life expectancy about 2.2 years with an annual, attributable per capita mortality rate of $133 / 100,000$ per year (Lelieveld et al., 2019). The World Health Organization (WHO) estimates the number of premature deaths which can be attributed to ambient air pollution is more than 4 million annually (WHO, 2018). It is not surprising, therefore, that the issue of the effects of air pollution on public health has become a significant topic worldwide.

HAPs and air toxicity have attracted increasing attention from the public in recent years. Toxic ingredients in the air may be released from various sources, such as mobile sources, stationary sources, and fugitive emissions (SCAQMD, 2015; 
Tsai et al., 2017). Six main emission source categories are identified as posing an emerging health risk in Europe (WHO, 2013). These are: road transport $(40.7 \%)$, space heating and air conditioning (15.0\%), shipping (8.8\%), energy production and distribution $(6.2 \%)$, industrial processes (metal industries) (6.2\%) and agriculture (5.3\%).

Many hazardous air pollutants are identified as carcinogenic by the International Agency for Research on Cancer (IARC) and are of concern to people and governments (IARC, 2019). Many elements in volatile organic compounds (VOCs) are harmful to humans. They can cause eye and skin irritation, and can be harmful to the bronchus. Some of these elements, such as benzene (identified as group I) are considered to be a particularly serious threat to public health (IARC, 1997). Benzene is a frequent by-product of the petrochemical industry, of the process of coking coal, the production of toluene, xylene and other aromatic compounds and in its role as a widely used industrial solvent. In addition, mobile motor exhaust is an important source of benzene in the environment (WHO, 2010). Another chemical that is considered to be a serious threat to public health is formaldehyde. Formaldehyde is an organic base chemical. Part of formaldehyde emission into the air is the result of the production of phenolformaldehyde in industry and the manufacture of low-cost urea-formaldehyde resins used in wood bonding. The use of these urea-formaldehyde resins results in the release of formaldehyde into the air from building materials, furniture, and household products (Salthammer, 2013; Lin et al., 2017; Shiue et al., 2018).

The U.S. EPA identifies six pollutants as being of greatest risk to American children (U.S. EPA, 2013). These are: formaldehyde, benzene, acetaldehyde, carbon tetrachloride, hexavalent chromium, and diesel particulate matter (DPM) (U.S. EPA, 2013). Formaldehyde, benzene, and hexavalent chromium are considered to be carcinogenic to humans, (NTP, 2011; U.S. EPA, 2011a, b). Acetaldehyde and carbon tetrachloride are also considered to be carcinogenic to humans (U.S. EPA, 2011c, d, 2013).

$2,3,7,8$-Tetrachlorodibenzo- $p$-dioxin $(2,3,7,8$-TCDD) is a by-product of incomplete combustion (such as the combustion of fossil fuels, biomass and municipal and industrial wastes) and is released into the environment. Soft-tissue sarcomas, lymphomas, and stomach carcinomas have been associated with exposure to 2,3,7,8-TCDD.

The main air emissions source for 1,3-butadiene in the USA are on-road and off road mobile vehicles (47 and 35\%, respectively), biomass burning (16\%), butadiene users $(1.2 \%)$, and petroleum refining (0.2\%) (U.S. EPA, 1996). Diesel exhaust particulate matters are able to induce cytokine/chemokine responses, cytokine inflammation, cellular oxidative stress, and have been shown to produce mutations in human hamster hybrid cells (Bao et al., 2007; Mazzarella et al., 2007; Øvrevik et al., 2010). Epidemiological studies have shown that an increase in particulate matter level is associated with increases in adverse cardiopulmonary effects (HEI, 2003; Pope III, 2004).

Arsenic species that are byproducts of human activities, such as coal burning, industrial waste disposal, the application of agricultural chemicals containing arsenic (such as insecticides, herbicides, algicides and growth promoters), the burning of wood treated with arseniccontaining preservatives, and preventive maintenance of the semiconductor manufacturing factory, are likely to have an important negative effect on public health (Environment Agency, 2008; Ham et al., 2017).

Particulate matter from diesel exhaust is the most ultrafine particulate matter. Most of this particulate matter is less than $0.1 \mu \mathrm{m}$ in size, a size which epidemiologic studies have shown to be harmful to human health. Some respiratory and cardiovascular effects (such as ischemic heart disease, lower respiratory infections, lung cancer, stroke, and chronic obstructive pulmonary disease (COPD).) are attributable to exposure to fine and ultrafine particulate matter (CE Delft, 2018). The health effects of diesel particulate matter are not only a consequence of their size but also of their constituents, including the PAHs, semi-volatile organic species and metals that could be potential carcinogen species.

In the Multiple Air Toxics Exposure Study IV (MATES IV) carried out by the Southern Coast Air Quality Management District (SCAQMD), results indicated that toxic elements in the air ranged from 320 to 480 parts per million and that diesel particulate matter is the major contributor to air toxic risk and accounts for about $68 \%$ of total air toxic risk (SCAQMD, 2015). According to the COPERT (Computer Programme to Calculate Emissions from Road Transport) emission factor study, the total cost of road traffic related air pollution in the EU28 in 2016 was $€ 66.7$ billion. The share of diesel vehicles in this cost was $83 \%$. Oxides of nitrogen $\left(\mathrm{NO}_{\mathrm{x}}\right)$ emissions have the largest share in the total cost (both health and non-health related) of air pollutants (65\%), followed by $\mathrm{PM}_{2.5}$ (32\%) (CE Delft, 2018).

This study determined the amount of hazardous air pollutants emitted by mobile sources, stationary sources, and port activities in the Xiaogang district of Kaohsiung, the second largest city in Taiwan. Six species of carcinogenic pollutants: benzene, formaldehyde, 1,3-butadiene, arsenic, 2,3,7,8-TCDD, and diesel particulate matter (DPM) were selected as the target pollutants of the study. Ambient concentrations of each kind of air pollution from various sources were simulated by the AERMOD model which is linked up with the Geographic Information System (GIS) to present the spatial characteristics of airborne pollutants. A cancer risk assessment was also conducted to evaluate the potential impact of air toxics on employee and residents in this industrial metropolitan region.

\section{MATERIALS AND METHOD}

\section{Study Area}

The study focused on the Xiaogang district of Kaohsiung, the second largest city in Taiwan. The population of the district is about 156,000 with a population density of more than 3400 people $\mathrm{km}^{-2}$. The Xiaogang district is a heavily industrialized district (chemical industry, iron and steel industry, refinery plant, and ship building companies etc.), heavily traffic loaded (motor vehicles and airport) and includes the Kaohsiung port complex area. Fig. 1 presents the major air pollution emission sources in the Xiaogang district. 


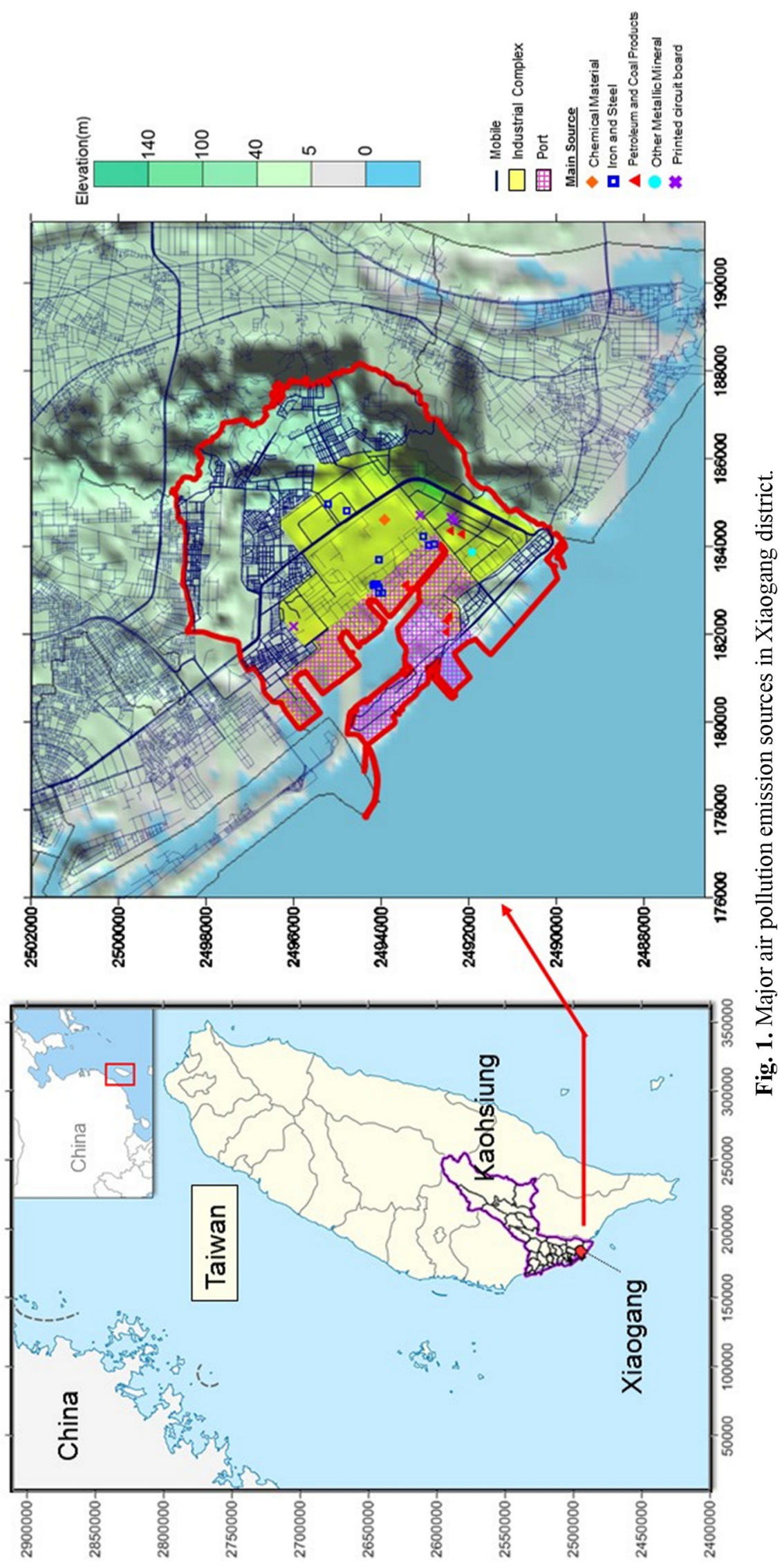




\section{Emission Estimation}

The Taiwan emission data system was established in 1992 and is updated every three years. The Taiwan emission data system (TEDs 8.0) was used for this study. According to the TEDs 8.0 in 2014, the emission of $\mathrm{PM}_{2.5}$ was 5,708 ton $\mathrm{yr}^{-1}$, $\mathrm{SO}_{\mathrm{x}}$ was 29,558 ton $\mathrm{yr}^{-1}, \mathrm{NO}_{\mathrm{x}}$ was 45,630 ton $\mathrm{yr}^{-1}, \mathrm{HC}$ was 61,890 ton $\mathrm{yr}^{-1}$, and $\mathrm{CO}$ was 83,996 ton $\mathrm{yr}^{-1}$ in Kaohsiung. The emission fraction for the Xiaogang district in Kaohsiung city was $42 \%$ for $\mathrm{PM}_{2.5}, 76 \%$ for $\mathrm{SOx}, 41 \%$ for $\mathrm{NO}_{\mathrm{x}}, 10 \%$ for $\mathrm{HC}$ and $14 \%$ for $\mathrm{CO}$. The emission loading is estimated to be 53 ton $\mathrm{yr}^{-1} \mathrm{~km}^{-2}$ for $\mathrm{PM}_{2.5}, 494$ ton $\mathrm{yr}^{-1} \mathrm{~km}^{-2}$ for $\mathrm{SO}_{\mathrm{x}}$, 411 ton $\mathrm{yr}^{-1} \mathrm{~km}^{-2}$ for $\mathrm{NO}_{\mathrm{x}}, 139$ ton $\mathrm{yr}^{-1} \mathrm{~km}^{-2}$ for $\mathrm{HC}$ and 260 ton $\mathrm{yr}^{-1} \mathrm{~km}^{-2}$ for $\mathrm{CO}$. It is a heavy industry and complex urban district.

\section{Source Database}

This study used the TEDS 8.0 data emission system to estimate hazardous air pollution, the AEROMOD model to simulate ambient air pollution concentration, and a cancer risk assessment to estimate the impact of air pollution on public health. Emissions from on-road mobile sources, stationary sources, and port operations were calculated examining the emission factors and activities of each source. On-road mobile sources include gasoline and diesel vehicles. For stationary sources, over 50 industrial plants and 59 process categories (totally about 630 processes) were selected to determine the emissions in Xiaogang District. Stationary sources included stack and fugitive emissions in the industrial complex. Port operations were including the operations of service equipment, vessels, off-road engines and on-road vehicles transportation inside the port area. Emission factors for each toxic air pollutant were derived from the SPECIATE 4.4 database, which had been developed by the U.S. EPA (2014). According to the Taiwan Emission Data System (TEDs), the uncertainty of emission data estimation could be identified as between class B (the variation was $\pm 20-60 \%$ ) and Class $C$ (the variation was $\pm 50-150 \%$ ) (TEPA, 2019).

\section{Scenarios}

Two emission scenarios were evaluated in this study, including a basic case and a controlled case. The basic case scenario 1 represented the emissions of stationary sources, mobile sources and port operations in base year (2014). This scenario focused on permitted emissions from stationary sources and reflected the emission condition on 2014 . Scenario 2 (control scenario) estimates the controlled emissions which would be resulted when an air pollution control plan was enforced. In this scenario the main strategies for reducing emissions from stationary sources included the renewal and improvement of air pollution control devices, VOCs emission audits by local environmental protection bureau of Kaohsiung and Taiwan Environmental Protection Agency, and emission reduction efforts, especially in the printed circuit board industry. The main strategies for reducing emissions from mobile sources included replacing old heavy-duty trucks and busses, converting vehicles from diesel to electricity, and implementing bus and bicycle policies in urban areas. For port operations, a port emission reduction program was conducted which involved increasing the shore electrical power supply and improving transport management and the work is audited by Kaohsiung Environmental Protection Bureau.

\section{Airborne Concentration Simulation}

The Gaussian dispersion model (AERMOD) (U.S. EPA, 2004) was used to simulate the ambient concentration of target hazardous air pollutants in this area. The requirements of modeling information were including the database containing emission inventory data from TEDs 8.0, the meteorological data from Kaohsiung station of the Center Weather Bureau and Xiaogang sounding station, the monitoring data from photochemical air monitoring stations of Taiwan EPA, and surface roughness from the inventory of National Land Surveying and Mapping Center, Ministry of the Interior, Taiwan. The coefficient of correlation $(\mathrm{R} \approx 1)$, normalized mean square error $(\mathrm{NMSE} \leq 0.5)$, fractional bias $(-0.5 \leq \mathrm{FB}$ $\leq 0.5)$, and factor of two $\left(\mathrm{Fa}_{2} \geq 0.8\right)$, were conducted to ensure the performance of the model simulation (U.S. EPA, 2004; Kumar et al., 2006). In addition, the photochemical air monitoring stations and industrial monitoring data were conducted to compare the results of model stimulation.

\section{Cancer Risk Assessment}

In this study, inhalation was assumed to be the main route by which residents of the area internalized air pollutants. Risk assessment focused on the chronic exposure to HAPs that may cause cancer, rather than on acute toxicity from exposure to HAPs.

Carcinogenic risks from chronic exposure were evaluated for each resident. The inhalation intake "I" was measured by the average daily intake during the exposure periods. Carcinogenic intake of HAPs for each resident was calculated as follows:

$I=\left(C_{i} \times I_{h} \times E_{t} \times E_{f} \times E_{d}\right) /\left(A_{t} \times B_{w}\right)$

where $\mathrm{I}$ is the inhalation intake $\left(\mathrm{mg} \mathrm{kg}^{-1}\right.$ day $\left.^{-1}\right), \mathrm{C}_{\mathrm{i}}$ is the $\mathrm{HAP}_{\mathrm{i}}$ species concentration in air $\left(\mathrm{mg} \mathrm{m}^{-3}\right)$ as obtained by the AEROMOD stimulation, $\mathrm{I}_{\mathrm{h}}$ is the inhalation rate $\left(\mathrm{m}^{3} \mathrm{~h}^{-1}\right)$, $\mathrm{E}_{\mathrm{t}}$ is the exposure time $\left(\mathrm{h}\right.$ day $\left.^{-1}\right), \mathrm{E}_{\mathrm{f}}$ is the exposure frequency (day year ${ }^{-1}$ ), $E_{d}$ is the exposure duration (year), $A_{t}$ is the average time ( 80 years $\times 365$ days year $\left.{ }^{-1}\right)$, and $B_{w}$ is the body weight ( $60 \mathrm{~kg}$ was assumed in this study). An average lifetime of 80 years was used for the HAPs carcinogenic assessment (although the average lifetime for the Taiwanese is about 78 years and the body weight could be $70 \mathrm{~kg}$, which could cause about a $10 \%$ difference in the measurement of cancer risk).

The lifetime cancer risks of various HAP species were calculated by incorporating exposure assessment and toxicity values (slope factors). Generally, the lifetime cancer risk was calculated as follows:

$\mathrm{C}_{\mathrm{r}}=\mathrm{I} \times \mathrm{S}_{\mathrm{f}}$

where $\mathrm{C}_{\mathrm{r}}$ is the cancer risk and $\mathrm{S}_{\mathrm{f}}$ is the cancer slope factor $\left(\mathrm{kg}\right.$-day $\left.\mathrm{mg}^{-1}\right)$. The inhalation cancer potency factor of benzene, formaldehyde, 1,3 butadiene, arsenic, 2,3,7,8-TCDD, and DPM is $1 \times 10^{-1}, 2.1 \times 10^{-2}, 6.0 \times 10^{-1}, 1.2 \times 10^{1}, 5.1 \times 10^{2}$,

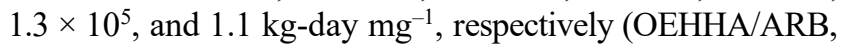


2015). The potential cancer risk and the cancer burden of hazardous air pollutants were evaluated by following a protocol developed by the California OEHHA (OEHHA, 2019). Six HAP species were conducted their individual cancer health risk and then summed up the synergism effects for the total health risk in this study.

\section{RESULT AND DISCUSSION}

Characteristics of Air Toxic Emission in the Study Region Emissions of six selected hazardous air pollutants from various sources are shown in Fig. 2. Results indicate the emission of benzene, formaldehyde, 1,3-butadiene, arsenic

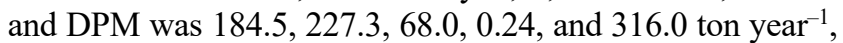
respectively. Furthermore, the emission of 2,3,7,8-TCDD was 4,994 mg-TEQ year ${ }^{-1}$. Fig. S1(a) shows the emissions from mobile sources.

Benzene. Benzene emission was $86.3 \%$ from mobile sources, $9.4 \%$ from harbor emissions and 3\% from industrial emissions. Motorcycles were the main source of benzene emissions: $49 \%$ from two-stroke and 32\% from four-stroke motorcycles (shown as Fig. S1). Only $3 \%$ of benzene was (a) Benzene

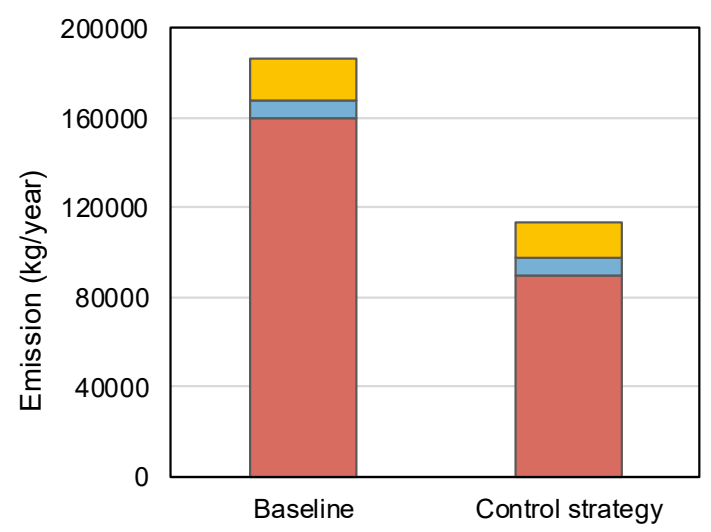

(c) 1,3-butadiene

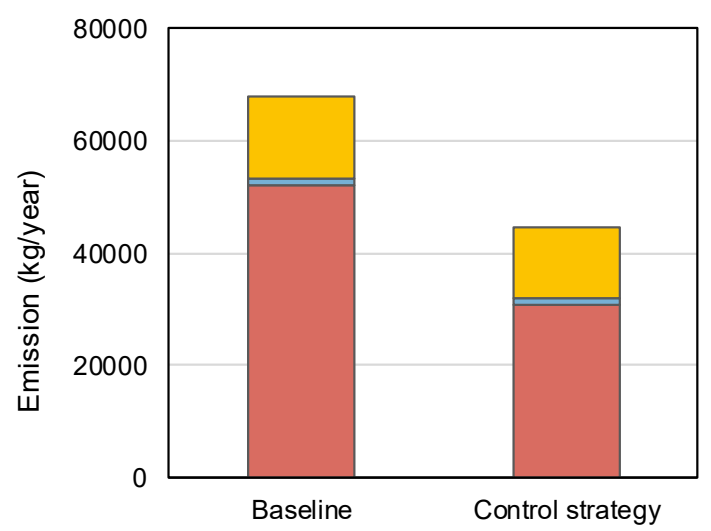

(e) DPM

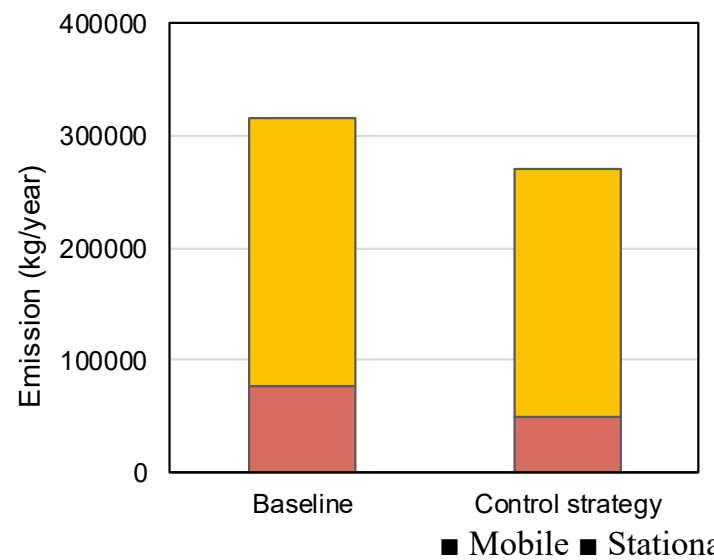

(b) Formaldehyde

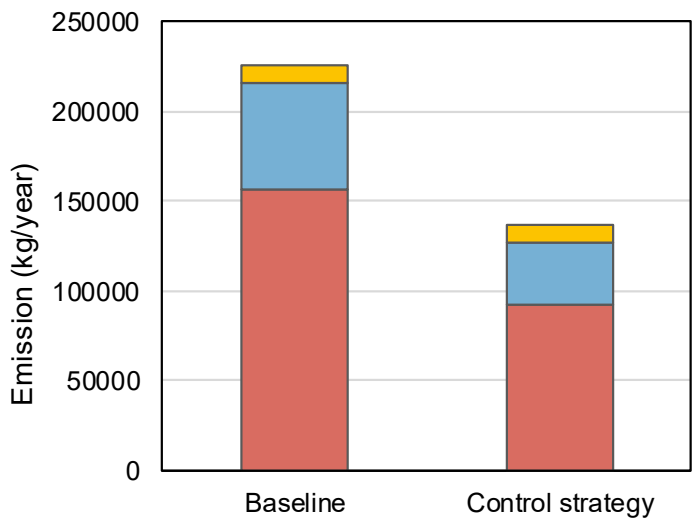

(d) Arsenic

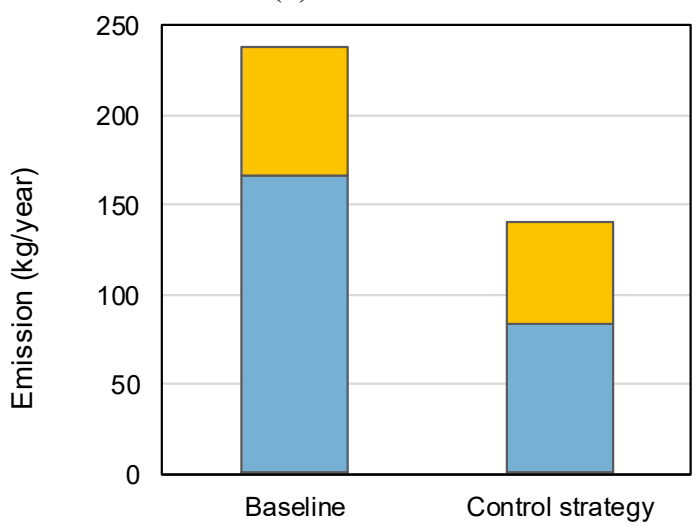

(f) 2,3,7,8-TCDD

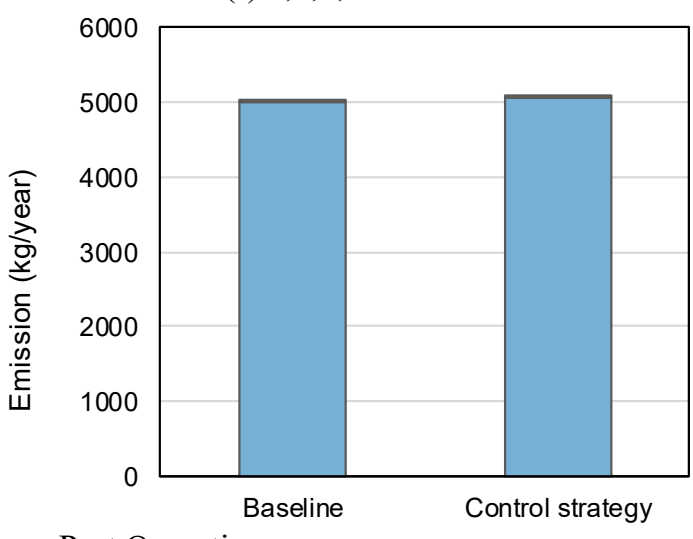

Fig. 2. Emission loading of mobile, stationary and port operations for baseline and control scenarios. 
emitted from stationary sources such as the iron and steel industry. Contributions from the chemical material and product industry were generally less than 1\% (shown as Fig. S1(b)). Ocean-going vessels $(7.3 \%)$ were the main source of emissions in harbor operations (shown as Fig. S1(c)).

Formaldehyde. Mobile sources were the main source $(69 \%)$ of formaldehyde due to their use of fuel. The sources of formaldehyde emissions were two-stroke (34\%) and fourstroke $(22 \%)$ motorcycles, heavy duty $(6.6 \%)$ vehicles and passenger (3.9\%) vehicles. In addition, $26 \%$ of formaldehyde emissions came from stationary sources: iron and steel industry:9.2\% and crude oil and coal industry: 16\%. About $5.1 \%$ of formaldehyde emissions came from harbor operations, especially from heavy duty vehicles $(4.3 \%)$.

1,3-butadiene. $77 \%$ of 1.3 -butadiene emissions came from mobile sources, $1.7 \%$ from stationary sources and $22 \%$ from harbor operations. Motorcycles (40\% for 2 -stroke and $26 \%$ for 4 -stroke motorcycles) and passenger vehicles $(8.8 \%)$ were the main sources of emission from mobile sources. The metal and mineral industry contributed $1.4 \%$ of 1.3 -butadiene emissions from stationary sources. In harbor operations, ocean-going vessels $(17.4 \%)$ were the main source of 1,3 butadiene.

Arsenic. Most arsenic emissions came from stationary sources in the iron and steel industry $(68.7 \%)$, while $30.7 \%$ came from the boilers of ocean-going vessels $(30.7 \%)$ in harbor operations.

Diesel particulate matter (DPM). $24 \%$ of DPM came from mobile sources and most of this matter was emitted from heavy duty vehicles (15.8\%), and heavy passenger vehicles (bus, $6.7 \%$ ). $76 \%$ of DPM was emitted from the harbor: $50.3 \%$ from ocean-going vessels, $12.3 \%$ from boat operations in the harbor and $11.2 \%$ from heavy duty vehicles.

2,3,7,8-TCDD. Most 2,3,7,8-TCDD is emitted from stationary sources in the iron and steel industry (100\%). (The sintering process in integrated steel plants and electric arc steel plants are the main sources of 2,3,7,8-TCDD).

An estimation of six target toxic air emissions showed that on-road mobile sources dominated the emissions of benzene (86.3\%), formaldehyde $(68.7 \%)$, and 1,3 -butadiene $(77 \%)$ in the study areas. Arsenic (69.8\%) and 2,3,7,8-TCDD (about $100 \%$ ) were mainly emitted from stationary sources. Most DPM was emitted from mobile diesel engines, and oceangoing vessels in port operations (shown as Fig. S1(c)). Mobile sources such as heavy duty diesel trucks and buses could be important sources of volatile organic compounds (VOCs), aldehydes, and particulate matters (Yao et al., 2015; Jin et al., 2017; Rojas-Mendoza et al., 2017; Jung et al., 2019).

\section{Airborne Concentration Stimulation of Six Species}

The AEROMOD model was employed to determine the ambient concentration of the six hazardous air pollutants which were studied. Fig. 3 shows the hazardous air pollutant concentrations as shown by the AERMOD stimulation. Fig. S2 presents the concentration distribution of the six hazardous air pollutants based on a grid stimulation. Fig. S3 indicates the spatial distribution of the six hazardous air pollutants emitted from mobile, stationary and port operations.

Benzene. The simulated average concentrations were
1.197, 0.028 and $0.090 \mu \mathrm{g} \mathrm{m}^{-3}$ from mobile, stationary, and port operations, respectively (shown as Table 1). The highest benzene concentrations could increase 5.7, 21 and 7.0 times their average mobile, stationary, and port concentrations. These concentrations could reach 3.10, 0.596, and $0.629 \mu \mathrm{g} \mathrm{m}^{-3}$, respectively.

Formaldehyde. The average formaldehyde concentration emitted from mobile, stationary, and port operations were $1.173, \quad 0.047,0.09 \mu \mathrm{g} \mathrm{m}^{-3}$, respectively. The highest concentrations could increase 5.3, 7.0 and 13 times to reach a concentration of $3.302,0.328$ and $1.14 \mu \mathrm{g} \mathrm{m}^{-3}$ from mobile, stationary, and port operations, respectively.

1,3 butadiene. For 1,3-butadiene, the average simulated concentration was $0.391,0.008$, and $0.068 \mu \mathrm{g} \mathrm{m}^{-3}$ for mobile, stationary and port operations, respectively. Highest concentrations could increase 5.6, 34.5 and 7.3 times to $1.011,0.276$ and $0.493 \mu \mathrm{g} \mathrm{m}^{-3}$ respectively.

Arsenic. For arsenic, the average concentration was $0.0066,0.1919$, and $0.3325 \mathrm{ng} \mathrm{m}^{-3}$ for mobile, stationary and port operations, respectively. Concentrations could increase to $0.017,2.94$, and $2.45 \mathrm{ng} \mathrm{m}^{-3}$ from mobile, stationary and port operations respectively.

DPM. For DMP, the average concentration was 0.570 and $1.271 \mu \mathrm{g} \mathrm{m}^{-3}$ from mobile, and port operations, respectively. The highest increment of DMP concentration could reach up to 1.46 and $9.03 \mu \mathrm{g} \mathrm{m}^{-3}$ from mobile, and port operations respectively.

2,3,7,8-TCDD. For 2,3,7,8-TCDD, the average concentration was 0.00776 and $0.00273 \mathrm{pg} \mathrm{m}^{-3}$, attributed to stationary and mobile sources, respectively. Concentrations could rise up to $1.95 \times 10^{-5}$ and $0.0143 \mathrm{pg} \mathrm{m}^{-3}$ for stationary and mobile sources respectively.

Spatial toxic air distribution indicated that the highest concentration of DMP, benzene, formaldehyde, and 1.3butadiene occurred in the vicinity of the highway and downtown area due to their heavy traffic.

The mean PCDD/F concentrations measured at an industrial park were significantly higher than those measured in other areas (Hung et al., 2018) and high gas fraction of PCDD/F that particulate matter in Taiwan (Lee et al., 2018). The higher chlorinated PCDD/Fs were primarily in the particle phase, and the fraction of particle phase PCDD/Fs increased with a decrease in temperature (Zhu et al., 2017).

According to the photochemical monitoring data, the average benzene concentration was $2.70 \mu \mathrm{g} \mathrm{m}^{-3}$ that could be $10-30 \%$ higher than the model stimulation. For, arsenic contents, the monitoring data could be 5 times of model stimulation. For dioxins, the monitoring data could be 10 times of model stimulation. The monitoring sampling sites near the emission sources could be one of the reasons of their high concentrations both arsenic and dioxins. In this work, both of arsenic and dioxins contents in particulate matter could be underestimation.

\section{Cancer Risk Analysis of Base Scenario}

Fig. 4 shows the cancer risk of different target air toxic species. The cancer risk of a 50th-percentile benzene concentration was $1.87 \times 10^{-5}$ and the highest cancer risk fraction was caused by mobile sources $\left(1.46 \times 10^{-5}\right)$. An 

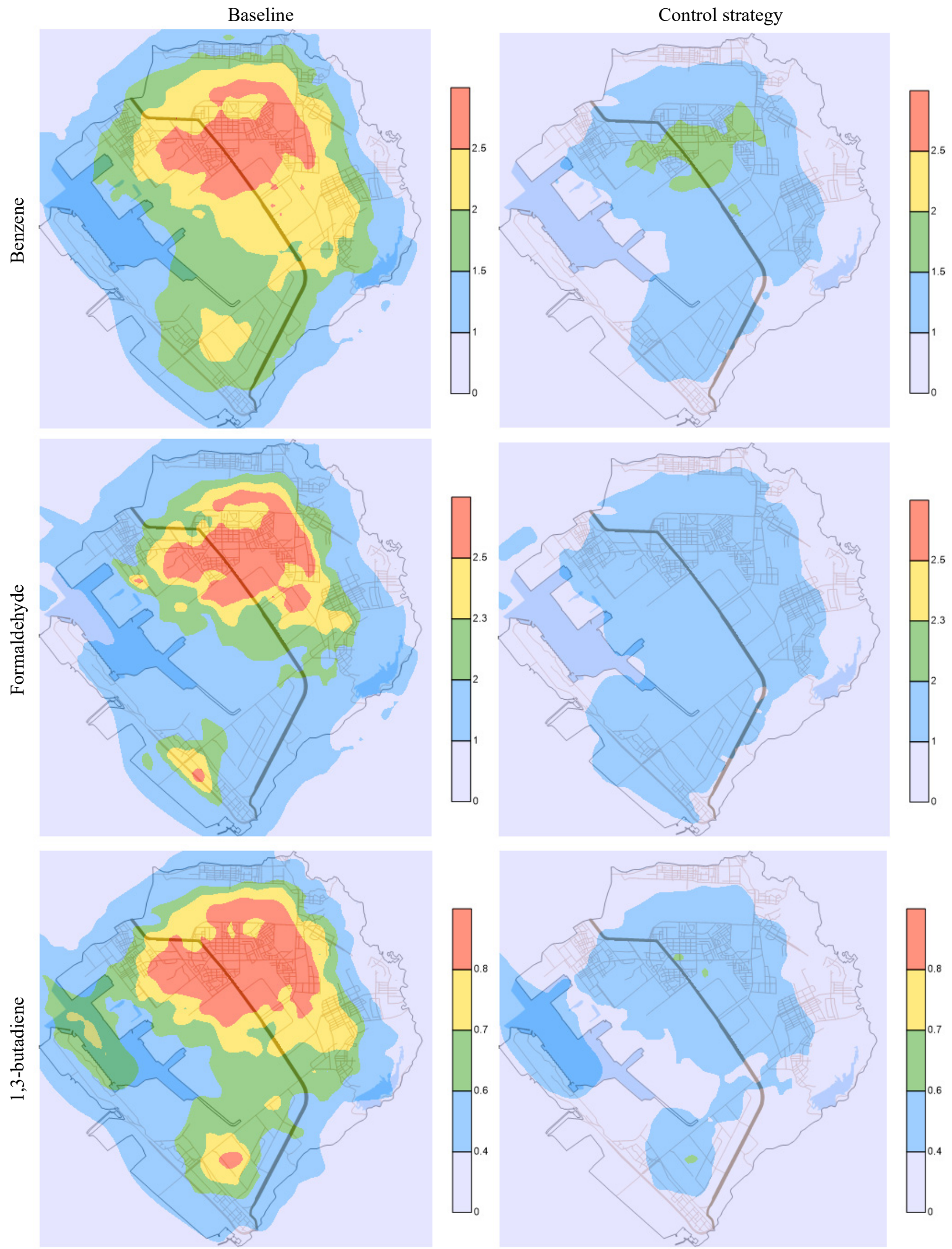

Fig. 3. Spatial distributions of six HAP concentrations from mobile, stationary and port operation for baseline and control scenarios (the unit of benzene, formaldehyde,1,3-butadiene, arsenic and DPM is $\mu \mathrm{g} \mathrm{m}^{-3} .2,3,7,8-\mathrm{TCDDis}_{\mathrm{pg} \mathrm{m}}{ }^{-3}$ ). 

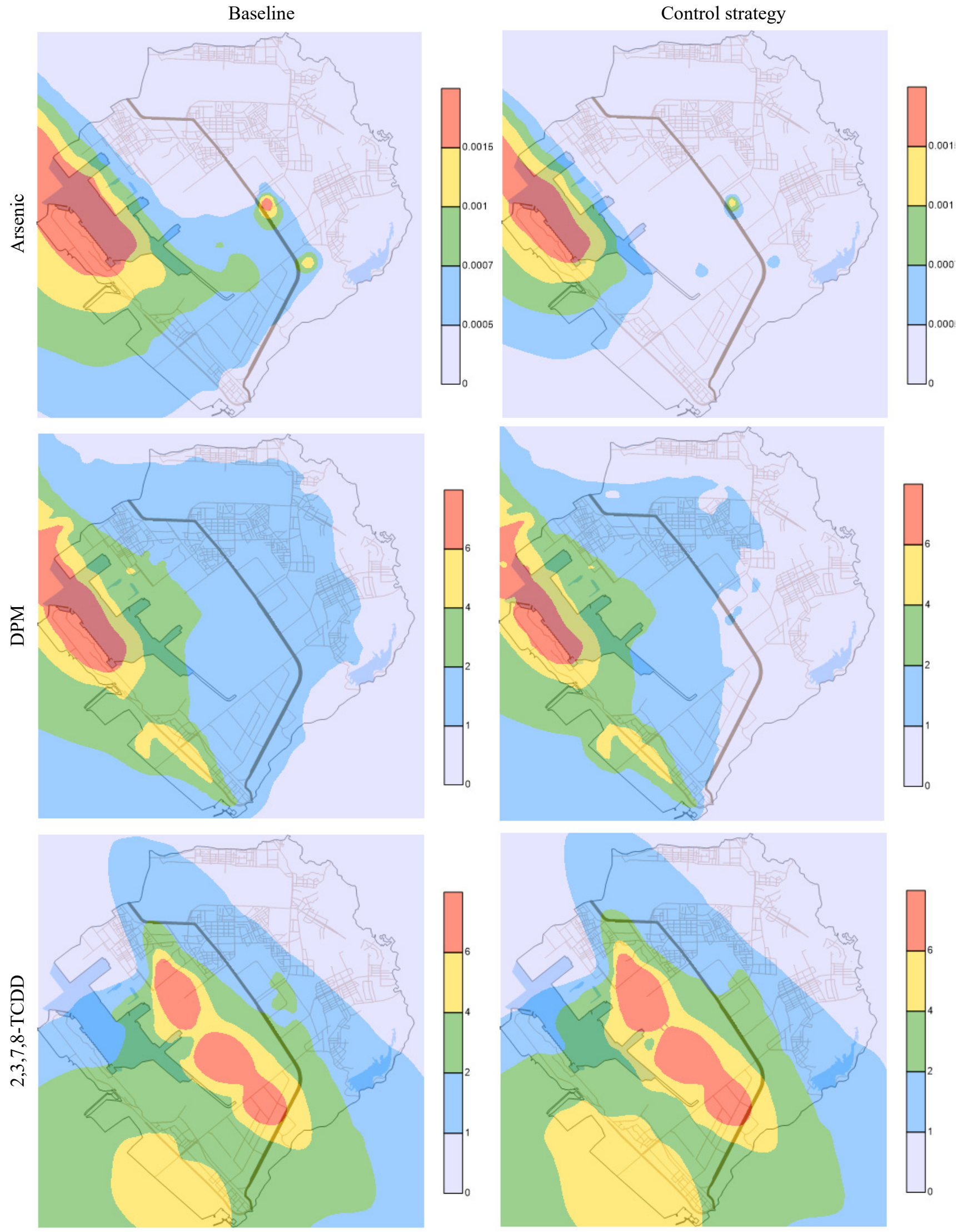

Fig. 3. (continued). 
Table 1. Concentration stimulation for different scenarios using the AERMOD model.

\begin{tabular}{|c|c|c|c|c|c|c|c|}
\hline \multirow{2}{*}{$\begin{array}{l}\text { HAPs } \\
\left(\mu \mathrm{g} \mathrm{m}^{-3}\right)\end{array}$} & \multirow{2}{*}{ Scenario } & \multicolumn{3}{|c|}{ Average concentration } & \multicolumn{3}{|c|}{ Maximums concentration } \\
\hline & & Mobile & Stationary & Port operations & Mobile & Stationary & Port operations \\
\hline \multirow[t]{2}{*}{ Benzene } & Baseline & 1.197 & 0.028 & 0.090 & 3.100 & 0.596 & 0.629 \\
\hline & Control strategy & 0.673 & 0.028 & 0.079 & 1.743 & 0.597 & 0.546 \\
\hline \multirow[t]{2}{*}{ Formaldehyde } & Baseline & 1.173 & 0.047 & 0.090 & 3.302 & 0.328 & 1.142 \\
\hline & Control strategy & 0.693 & 0.039 & 0.098 & 1.789 & 0.322 & 1.232 \\
\hline \multirow{2}{*}{ 1,3-butadiene } & Baseline & 0.391 & 0.008 & 0.068 & 1.011 & 0.276 & 0.493 \\
\hline & Control strategy & 0.229 & 0.008 & 0.059 & 0.593 & 0.277 & 0.428 \\
\hline Arsenic & Baseline & 0.0066 & 0.1919 & 0.3325 & 0.0179 & 2.9400 & 2.4461 \\
\hline$\left(\mathrm{ng} \mathrm{m}^{-3}\right)$ & Control strategy & 0.0042 & 0.0953 & 0.2687 & 0.0109 & 1.4573 & 1.9707 \\
\hline \multirow[t]{2}{*}{ DPM } & Baseline & 0.587 & 0 & 1.271 & 1.465 & 0 & 9.036 \\
\hline & Control strategy & 0.382 & 0 & 1.190 & 0.953 & 0 & 8.646 \\
\hline 2,3,7,8-TCDD & Baseline & $7.404 \times 10^{-6}$ & $2.717 \times 10^{-3}$ & 0 & $1.95 \times 10^{-5}$ & 0.0143 & 0 \\
\hline$\left(\mathrm{pg} \mathrm{m}^{-3}\right)$ & Control strategy & $7.112 \times 10^{-6}$ & $2.852 \times 10^{-3}$ & 0 & $1.87 \times 10^{-5}$ & 0.0167 & 0 \\
\hline
\end{tabular}

estimate of a $95 \%$ cancer risk reached $3.66 \times 10^{-5}$. Fig. S4 presents the cancer risk distribution based on a grid determination. The spatial cancer risks were caused by different hazardous air pollutants as shown in Fig. S5.

For formaldehyde, the 50th-percentile cancer risk was $4.03 \times 10^{-6}$ and most cancer risk was attributed to mobile sources. The $95 \%$ cancer risk reached $8.27 \times 10^{-6}$.

For 1,3-butadiene, the 50th-percentile cancer risk was 4.43 $\times 10^{-5}$. Mobile sources and port operations were the main sources of risk. The $95 \%$ cancer risk could be about 1.76 times the 50th-percentile cancer risk and reach $7.78 \times 10^{-5}$.

For arsenic, the 50th-percentile cancer risk was $7.29 \times 10^{-7}$. Stationary sources and port operations were the main sources of cancer risk. The $95 \%$ cancer risk could be 5 times more than the 50th-percentile cancer risk and reach $4.01 \times 10^{-6}$. For DPM, the 50th-percentile cancer risk was $2.85 \times 10^{-4}$. Mobile sources and port operations were the main sources of cancer risk. The $95 \%$ cancer risk could be 4 times more than the 50th-percentile cancer risk and reach $1.47 \times 10^{-3}$.

For 2,3,7,8-TCDD, the 50th-percentile cancer risk was $9.17 \times 10^{-8}$ and stationary sources were the main sources of cancer risk. The $95 \%$ cancer risk could be about 2 times the 50th-percentile cancer risk and reach $1.58 \times 10^{-7}$.

The spatial distribution of potential cancer risk is presented as Fig. 2. At a 50th- percentile concentration level, the cancer risk of benzene, formaldehyde and 1,3-butadine came mainly from mobile sources, and their cancer risk was over $10^{-6}$. The DPM was dominantly emitted from mobile sources and port operations and the cancer risk was over $10^{-4}$. At a $95 \%$ percentile concentration, the cancer risks of most air toxic species from different sources were higher than $10^{-6}$. Besides arsenic from stationary sources, DPM from stationary sources, and 2,3,7,8-TCDD from all sources had a cancer risk of less than $10^{-6}$. The sum of the cancer risk of all six species from the three sources examined in this study reached $4.93 \times 10^{-4}$ at the 50th-percentile concentration mark and $1.85 \times 10^{-3}$ at the 95 percentile concentration mark (shown as Table 2). The cancer risk came mainly came from the DPM emissions from mobile sources and port operations in the Xiaogang district (shown as Table 3). Among the six toxic air emissions examined in this study, DPM presented the highest cancer risk. DPM contributed more than $80 \%$ of total cancer risk, followed by 1,3-butadiene, benzene, formaldehyde, arsenic, and 2,3,7,8-TCDD.

In the industrial and resident complex area about $99 \%$ of cancer risk can be attributed to on-road vehicles and port operations. Cancer risk caused by stationary sources would be much less than those caused by all the mobile sources in the area.

In this study, the cancer risk was synergism by six HAPs in Xiaogang district and its estimate of a 95\% cancer risk reached $1.85 \times 10^{-3}$. To compare with other works, such as Ren-Da industrial park in Kaohsiung the cancer risk was $4.55 \times 10^{-5}(\mathrm{IDB}, 2015)$ and the cancer risk of Mailiao Industrial Complex (petrochemical industrial park) in Yunlin was $1.27 \times 10^{-5}$ (FPG, 2016). Both of other works indicated the cancer risk were lower than the risk in this study. It could be attribution to the DPM was not evaluated for its risk in other studies that could be underestimation.

\section{Control Scenario Comparison}

The stringent emission regulation is planned for refinery plants to reduce the formaldehyde emission. The iron and steel plants were conducted the emission reduction program and reduce the coal consumption to eliminate the arsenic emission.

Due to the effect of stringent regulation of mobile sources, emission of benzene, formaldehyde, and 1,3-butadiene were decreased significantly. Emission of DPM was also decreased around $10 \%$ both from on-road trucks and vessel emissions.

The control scenario shows that $39 \%$ benzene, $39 \%$ formaldehyde, 34\% 1,3-butadiene and 15\% DPM emissions could be reduced compared to the emissions reported in the baseline scenario (shown as Fig. 2). The control scenario does show an increase $1.3 \%$ 2,3,7,8-TCDD emissions compared to the baseline scenario.

Air model simulation results indicate that emission reduction of these target toxic air pollutants from mobile sources may lower the cancer burden of residents in the study area. Reducing DPM emissions from on-road diesel trucks could lower the cancer risk for the residents along the transportation routes. Controlling toxic air emissions from all sources in port operations and vessels could lower the cancer risk for all humans in the industrial metropolitan area. 

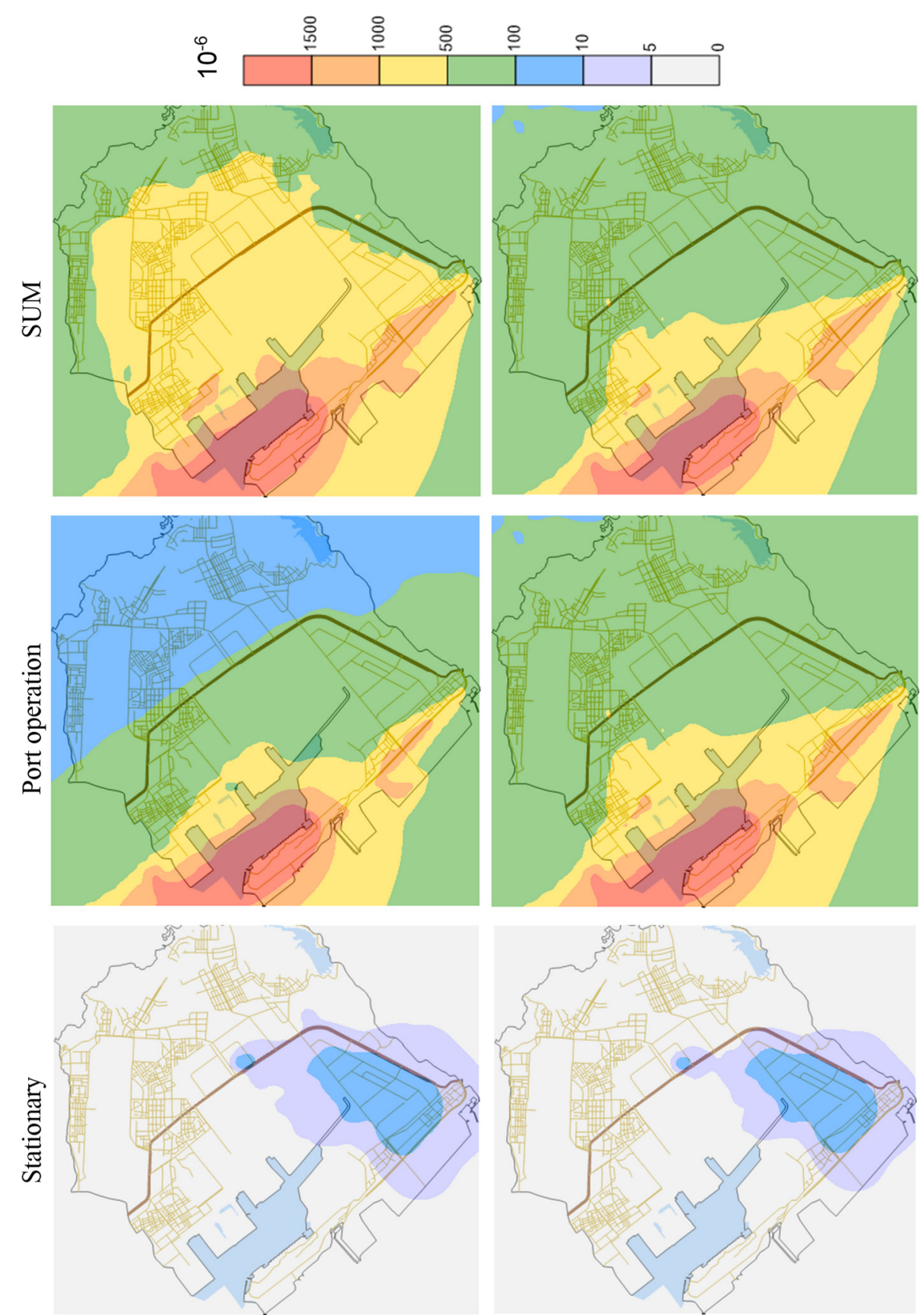

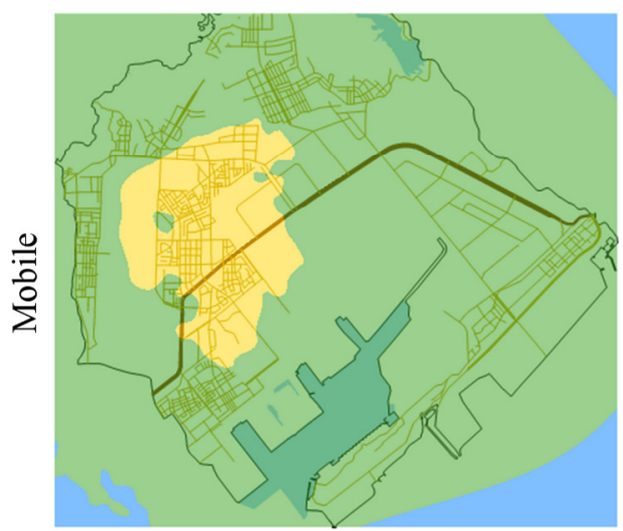

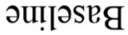
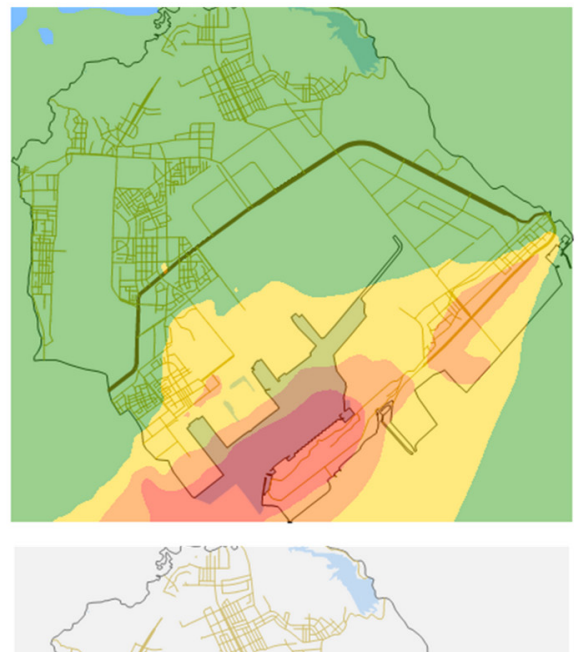

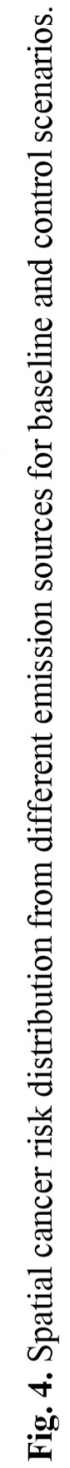

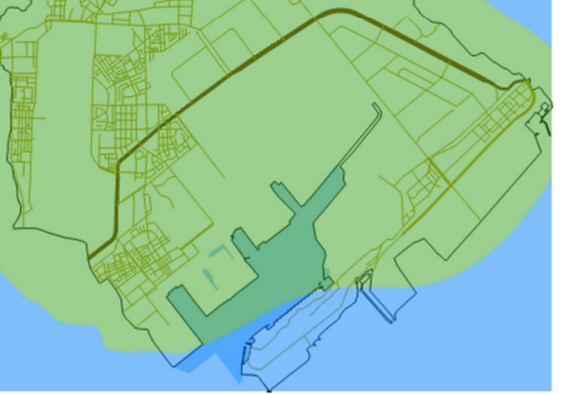

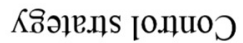




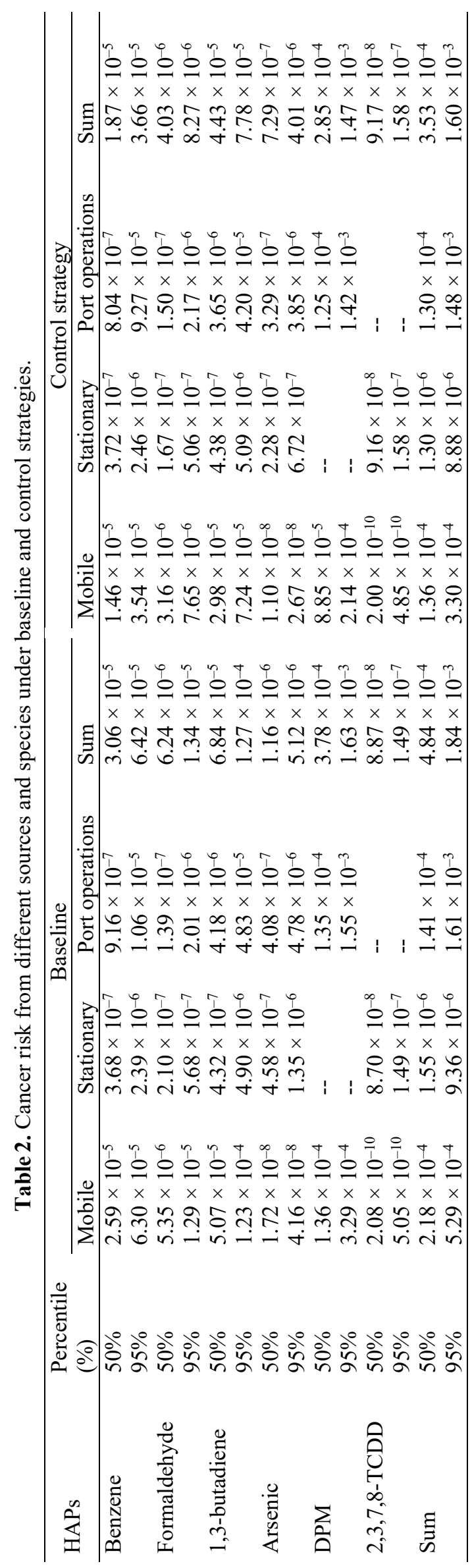

Based on the cancer risk assessment, it appears that DPM could be the highest risk species from port operations and diesel motor vehicles could be the main sources of DPM elsewhere. Consequently the control scenario focused on reducing diesel fuel consumption of docked vessels in the port by replacing the use of diesel with electricity supplied from the mainland, by applying stringent emissions regulations in refinery plants to reduce formaldehyde emissions, and applying an emissions reduction program in iron and steel plants to reduce coal consumption and thereby eliminate arsenic emissions. Despite all of these efforts the risk of cancer was only reduced by $10-15 \%$. Policy makers will have to think carefully about whether implementing the kind of emissions regulations simulated in this control scenario will need to be enhanced with additional measures to further reduce the risk of air pollution for human health.

Emissions reductions from the port diesel trucks can be obtained by fleet modernization through the installation of diesel particulate filters $(\mathrm{DPFs}), \mathrm{NO}_{\mathrm{x}}$ reduction technologies, oxidation catalysts, or other effective control strategies such as cleaner fuels (ARB, 2006). Usually, trucks were operated for local or regional services at ports and they were typically older models with much higher mileage that the trucks were employed for long haul activities. The older higher emitting engines were replacement with newer cleaner emitting engines by repowering or replacing the existing truck is the most effective strategy, although significantly more expensive, for reducing $\mathrm{PM}, \mathrm{NO}_{\mathrm{x}}$ and other airborne pollutant emissions (ARB, 2006). For port operation, the use of cleaner fuels for hoteling and cold ironing could be conducted for the oceangoing vessels, the cleaner fuels, retrofit with add-on control equipment, and repower engines could be applied to tugboats and towboats and the cleaner fuels, retrofit equipment, replace or repower equipment, Idle reduction measures, and Improved gate efficiency could be used for land-based cargo equipment (U.S. EPA, 2005). The development of effective DPM emission control strategies can significantly reduce the health risk in the area.

\section{CONCLUSIONS}

According to the Taiwan emission data system (TEDs $8.0,2014)$ the emission of benzene, formaldehyde, 1,3butadiene, arsenic and DPM was 184, 227, 68.0, 0.238, and 316 ton year $^{-1}$, respectively, and the 2,3,7,8-TCDD was 4,994 $\mathrm{mg}^{-T E Q}$ year ${ }^{-1}$ in the Xiaogang district. An emission estimation of six target toxic air pollutants showed that onroad mobile sources dominated the emissions of benzene (86\%), formaldehyde (697\%), and 1,3-butadiene (77\%) in the Xiaogang area. Arsenic (70\%) and 2,3,7,8-TCDD (about $100 \%$ ) were mainly emitted from stationary sources. Based on a cancer risk assessment, the DPM appears to be the highest risk species and most DPM was emitted from port operations, ocean-going vessels and the diesel engines of vehicles. In the study's control scenario electricity was supplied to vessels in berth to reduce DPM emissions, stringent regulations were applied to reduce formaldehyde emissions from refinery facilities and steps taken to reduce arsenic emissions from iron and steel plants. $95 \%$ of total cancer risk 
Table 3. Cancer risk fraction (\%) of different HAPs based on the same emission sources and scenarios.

\begin{tabular}{llllllll}
\hline Sources & Scenarios & Benzene & formaldehyde & 1,3 -butadiene & Arsenic & DPM & $2,3,7,8$-TCDD \\
\hline Mobile & Baseline & 12.0 & 2.46 & 23.4 & 0.01 & 62.1 & 0 \\
& Control strategy & 10.8 & 2.32 & 22.0 & 0.01 & 64.8 & 0 \\
Stationary & Baseline & 24.5 & 8.82 & 43.0 & 20.5 & 0 & 3.14 \\
& Control strategy & 27.9 & 8.10 & 49.0 & 11.3 & 0 & 3.67 \\
Port operations & Baseline & 0.62 & 0.13 & 2.79 & 0.27 & 96.2 & 0 \\
& Control strategy & 0.58 & 0.15 & 2.60 & 0.24 & 96.4 & 0 \\
\hline
\end{tabular}

Note: fractions less than 0.01 is presented as zero.

was reduced $10-15 \%$ from $1.84 \times 10^{-3}$ to $1.60 \times 10^{-3}$. More effective control measures are necessary to reduce the risk of cancer in the area.

\section{ACKNOWLEDGEMENTS}

The authors express their sincere thanks to the Ministry of Science and Technology, Executive Yuan, Republic of China (Taiwan) for research fund support (MOST 104-2221-E006-020-MY3).

\section{SUPPLEMENTARY MATERIAL}

Supplementary data associated with this article can be found in the online version at http://www.aaqr.org.

\section{REFERENCES}

Air Resources Board (ARB) (2016). California. 2006. Evaluation of Port Trucks and Possible Mitigation Strategies. Sacramento, CA.

Bao, L., Chen, S., Wu, L., Hei, T.K., Wu, Y., Yu, Z. and Xu, A. (2007). Mutagenicity of diesel exhaust particles mediated by cell-particle interaction in mammalian cells. Toxicology 229: 91-100. doi: 10.1016/j.tox.2006.10.007.

CE Delft (2018). Health impacts and costs of diesel emissions in the EU. Delft, CE Delft, November 2018.

Environment Agency (2008). A review of the toxicity of arsenic in air. Science Report - SC020104/SR4. Bristol, UK, 2008.

European Environment Agency (EEA) (2018). Air quality in Europe - 2018 report, Copenhagen, Denmark.

Formosa Plastics Group (FPG) (2016). Health risk assessment of hazardous air pollutants in the vicinity Mailiao industrial complex. Yunlin, Taiwan (in Chinese)

Ham, S., Yoon, C., Kim, S., Park, J., Kwon, O., Heo, J., Park, D., Choi, S., Kim, S., Ha, K. and Kim, W., (2017) Arsenic Exposure during Preventive Maintenance of an Ion Implanter in a Semiconductor Manufacturing Factory. Aerosol Air Qual. Res. 17: 990-999.

HEI (Health Effects Institute) (2003). Revised analyses of time-series studies of air pollution and health. Special Report. Health Effects Institute, Boston.

Hung, N.T., Ting, H.W. and Chi, K.H. (2018). Evaluation of the relative health risk impact of atmospheric PCDD/Fs in $\mathrm{PM}_{2.5}$ in Taiwan. Aerosol Air Qual. Res. 18: 2591-2599.

Industrial Development Bureau (IDB) (2015). Health risk assessment in the vicinity of Ren-Da Industrial Park,
Taipei. Ministry of Economic Affairs, Taiwan (in Chinese). International Agency for Research on Cancer (IARC) (1997). Monographs. "Benzene”, vol. 29, pp. 93-148, pp. 391-398. International Agency for Research on Cancer (IARC) (2019). Monographs on the identification of carcinogenic hazards to humans. https://monographs.iarc.fr/list-of-classificationsvolumes/, Last Access: May 2019.

Jin, T., Lu, K., Liu, S., Zhao, S., Qu, L. and Xu, X. (2017). Chemical characteristics of particulate matter emission from a heavy-duty diesel engine using ETC cycle dynamometer test. Aerosol Air Qual. Res. 17: 406-411.

Jung, S., Mun, S., Chung, T., Kim, S., Seo, S., Kim, I., Hong, H., Chong, H., Sung, K., Kim, J. and Hong, Y. (2019). Emission characteristics of regulated and unregulated air pollutants from heavy duty diesel trucks and buses. Aerosol Air Qual. Res. 19: 431-442.

Kumar, A., Dixit, S., Varadarajan, C., Vijayan, A. and Masuraha, A. (2006). Evaluation of the AERMOD dispersion model as a function of atmospheric sability for an urban area. Environ. Prog. 25: 141-151.

Lee, Y.Y., Wang, L.C., Zhu, J., Wu, J.L. and Lee, K.L. (2018) Atmospheric $\mathrm{PM}_{2.5}$ and polychlorinated dibenzop-dioxins and dibenzofurans in Taiwan. Aerosol Air Qual. Res. 18: 762-779.

Lelieveld, J., Klingmüller, K., Pozzer, A., Pöschl, U., Fnais, M., Daiber, A. and Münzel, T. (2019). Cardiovascular disease burden from ambient air pollution in Europe reassessed using novel hazard ratio functions. Eur. Heart J. 40: 1590-1596.

Lin, H., Chen, D., Liu, H., Zou, X. and Chen, T. (2017). Effect of $\mathrm{MnO}_{2}$ crystalline structure on the catalytic oxidation of formaldehyde. Aerosol Air Qual. Res. 17: 1011-1020.

Mazzarella, G., Ferraraccio, F., Prati, M.V., Annuniziata, S., Bianco, A., Mezzogiorno, A., Liguori, G., Angelillo, I.F. and Cazzola, M. (2007). Effect of diesel exhaust particles on human lung epithelial cells: An in vitro study. Respir. Med. 101: 1155-1162, doi: 10.1016/j.rmed.2006.11.011.

National Toxicology Program (NTP) (2011). Report on Carcinogens, 12th Edition. U.S. Department of Health and Human Services, National Toxicology Program. Research Triangle Park, NC. http://ntp.niehs.nih.gov/ntp/ roc/twelfth/roc12.pdf.

OEHHA (2019). Air toxics hot spots program risk assessment guidelines. https://oehha.ca.gov/air/air-toxicshot-spots, Last Access: March 2019.

OEHHA/ARB (2015). http://www.arb.ca.gov/toxics/healt hval/healthval.htm, Last Access: 13 May 2015. 
Organisation for Economic Co-operation and Development (OECD) (2015). Economic cost of the health impact of air pollution in Europe: Clean air, health and wealth. WHO Regional Office for Europe, Copenhagen.

Øvrevik, J., Arlt, V.M., Øya, E., Nagy, E., Mollerup, S., Phillips, D.H., Lag, M. and Holme, J.A. (2010). Different effects of nitro-PAHs and amino-PAHs on cytokine and chemokine responses in human bronchial epithelial BEAS-2B cells. Toxicol. Appl. Pharmacol. 242: 270-280, doi: 10.1016/j.taap.2009.10.017.

Pope III, C.A., Burnett, R.T., Thurston, G.D., Thun, M.J., Calle, E.E. and Krewski, D. (2004). Cardiovascular mortality and long-term exposure to particulate air pollution. Circulation 109: 71-77, doi: 10.1161/01.CIR.0 000108927.80044.7F.

Rojas-Mendoza, L., Sarver, E.A. and Saylor, J.R. (2017) Removal of DPM from an air stream using micron-scale droplets. Aerosol Air Qual. Res. 17: 1865-1874.

Salthammer, T. (2013). Formaldehyde in the ambient atmosphere: From an indoor pollutant to an outdoor pollutant? Angew. Chem. Int. Ed. 52: 3320-3327, doi: 10.1002/anie.201205984.

Shiue, A., Hu, S.C., Tseng, C. H., Chuang, C.M. and Leggett, G. (2018). Assessment of adsorptive filter for removal of formaldehyde from indoor air. Aerosol Air Qual. Res. 18: 3147-3164.

Southern Coast Air Quality Management District (SCAQMD) (2015). Multiple Air Toxics Exposure Study IV (MATES IV), Final Report. Diamond Bar, CA.

Taiwan Environmental Protection Agency (TEPA) (2019). Taiwan Air Pollutants Emission Data System, https://teds. epa.gov.tw/Introduction.aspx Last Access: 26 September 2019.

The World Bank (2016). The cost of air pollution: Strengthening the economic case for action. Washington DC, USA.

Tsai, J.H., Yao, Y.C., Huang, P.H. and Chiang, H.L. (2017). Criteria pollutants and volatile organic compounds emitted from motorcycle exhaust under various regulation phases. Aerosol Air Qual. Res. 17: 1214-1223.

U.S. Environmental Protection Agency (U.S. EPA) (1996). Locating and estimating air emissions from sources of 1,3-Butadiene, EPA 454/R-96-008, Eastern Research Group, North Carolina.

U.S. Environmental Protection Agency (U.S. EPA) (2004). Emissions monitoring and analysis division, AERMOD: DESCRIPTION OF MODEL FORMULATION, Office of Air Quality Planning and Standards, Research Triangle Park, NC, Publication No. EPA-454/R-03-004.

U.S. Environmental Protection Agency (U.S. EPA) (2005). The Philadelphia Port - Diesel Particulate Emissions Sources and Potential Control Measures. Chapel Hill, NC.
U.S. Environmental Protection Agency (U.S. EPA) (2011a). IRIS Summaries: Benzene (CASRN 71-43-2). U.S. EPA, National Center for Environmental Assessment. http://www.epa.gov/iris/subst/0276.htm, Last Access: 6 June 2011.

U.S. Environmental Protection Agency (U.S. EPA) (2011b). IRIS Summaries: Chromium (VI) (CASRN 18540-29-9). U.S. EPA, national center for environmental assessment. http://www.epa.gov/iris/subst/0144.htm, Last Access: 6 June 2011.

U.S. Environmental Protection Agency (U.S. EPA) (2011c). IRIS Summaries: Acetaldehyde (CASRN 75-07-0). U.S. EPA, National Center for Environmental Assessment. http://www.epa.gov/iris/subst/0290.htm. Last Access: 6 June 2011.

U.S. Environmental Protection Agency (U.S. EPA) (2011d). IRIS summaries: Carbon tetrachloride (CASRN 56-23-5). U.S. EPA, National Center for Environmental Assessment. http://www.epa.gov/iris/subst/0020.htm. Last Access: 9 August 2011.

U.S. Environmental Protection Agency (U.S. EPA) (2013). America's children and the environment. Washington, DC, USA.

U.S. Environmental Protection Agency (U.S. EPA) (2014). SPECIATE version 4.4 database development documentation. Research Triangle Park, NC, EPA/600/R$13 / 307$.

World Health Organization (WHO) (2010). Exposure to benzene: A major public health concern. Geneva 27, Switzerland.

World Health Organization (WHO) (2013). Health risks of air pollution in Europe - HRAPIE project. Copenhagen, Denmark.

World Health Organization (WHO) (2018). Ambient (outdoor) air quality and health. http://www.who.int/newsroom/fact-sheets/detail/ambient-(outdoor)-air-quality-andhealth, Last Access: 13 July 2018.

Yao, Z., Jiang, X., Shen, X., Ye, Y., Cao, X., Zhang, Y. and He, K. (2015), On-road emission characteristics of carbonyl compounds for heavy-duty diesel trucks. Aerosol Air Qual. Res. 15: 915-925.

Zhu, J., Xing, J., Tang, H., Lee, W.J., Yan, P., Cui, K. and Huang, Q. (2017). Atmospheric deposition of polychlorinated dibenzo- $p$-dioxins and dibenzofurans in two cities of northern China. Aerosol Air Qual. Res. 17: 2027-2040.

Received for review, August 30, 2019

Revised, October 8, 2019

Accepted, October 11, 2019 